\title{
REHABILITASI SALURAN TERSIER DESA SUKOANYAR PAKIS KABUPATEN MALANG
}

\author{
Eko Noerhayati 1), Bambang Suprapto ${ }^{2)}$ \\ ${ }^{1,2}$ Jurusan Teknik Sipil, Universitas Islam Malang \\ email: eko.noerhayati@unisma.ac.id; bambangsup.unisma@gmail.com
}

\begin{abstract}
The rehabilitation channel carried out in Sukoanyar Village aims to improve the welfare of community empowerment and farmer development. Farmer's empowerment and development is improving tertiary irrigation network infrastructure, which increases yields. Proper irrigation channels can make irrigation water needs in the fields. This activity in 2020 collaboration with farmer groups and the City of Malang Public Works Water Resources Office. This activity is in partnership with the Sukoanyar Village Farmer Group, namely the Dewi Ratih I Farmer Group. According to the observation, he identified the problem Adalahn partners. In essence, the lack of some facilities in the tertiary irrigation network and absence management system is how to operate and maintain the tertiary canals. The solution offered is the repair facility on the channel. The repair is carried out infrastructure repairs of the irrigation network in the tertiary canal broke. The method of this activity is the community approach. The implementation stage is divided into three events, namely, planning, preparation, and execution of construction. At the end of the corresponding channel, activities resulted in the improvement of technical provisions so that the circuit can drain water into the fields correctly and impact on increasing yields.
\end{abstract}

Keywords: Rehabilitation, irrigation, farming, tertiary

\begin{abstract}
ABSTRAK
Rehabilitasi saluran tersiar di Desa Sukoanyar bertujuan untuk meningkatkan kesejahteraan masyarakat desa melalui pemberdayaan dan pembinaan petani. Pemberdayaan dan pembinaan petani dilakukan melalui perbaikan sarana jaringan irigasi guna peningkatan hasil panen dengan cara efisiensi kebutuhan air irigasi teknis dengan perbaikan saluran tersier. Kegiatan ini dilakukan pada tahun 2020 bekerjasama dengan kelompok tani dan Dinas Pekerjaan Umum Sumber Daya Air Kabupaten Malang. Kegiatan ini dilakukan pada salah satu kelompok tani yang ada di desa Sukoanyar yaitu kelompok tani Dewi Ratih I. Berdasarkan pengamatan masalah mitra yang terindentifikasi pada survei antara lain: kurangnya beberapa sarana pada jaringan irigasi tersier dan kwarter yang vital, belum adanya sistem manajemen terutama penentuan pola tanam, kelembagaan kelompok tani yang masih lemah. Solusi yang ditawarkan adalah perbaikan fasilitas. Perbaikan-perbaikan tersebut adalah pada sub sistem pengadaan perbaikan sarana jaringan irigasi di saluran tersier yang sudah rusak. Metode pelaksanaan kegiatan ini dilakukan dengan pendekatan pada masyarakat. Tahap pelaksanaan dibagi menjadi 3 kegiatan yaitu perencanaan, persiapan dan pelaksanaan konstruksi. Pada akhir kegiatan dihasilkan saluran tersier yang telah diperbaiki sesuai dengan ketentuan teknis sehingga saluran dapat mengalirkan air ke sawah dengan baik yang berdampak pada peningkatan hasil panen.
\end{abstract}

Kata kunci: Rehabilitasi, irigasi, tani, tersier

\section{PENDAHULUAN}

Dalam rangka mendukung program Ketahanan Pangan Nasional dan upaya peningkatkan kemampuan ekonomi serta kesejahteraan masyarakat melalui pemberdayaan masyarakat tani maka perlu adanya sarana jaringan irigasi yang baik. Meskipun Kementerian Pekerjaan Umum melalui Direktorat Jenderal Sumber Daya Air 
telah melaksanakan Program Percepatan dan Perluasan Pembangunan Infrastruktur Sumber Daya Air pada Irigasi Kecil (P4-ISDA-IK) pada tahun 2015 namun ternyata saat ini masih cukup banyak jaringan kecil yaitu saluran tersier yang sudah tidak memenuhi standart secara teknis sehingga perlu adanya rehabilitasi jaringan irigasi terutama pada saluran tersier.

Desa Sukoanyar adalah salah satu desa di Kecamatan Pakis, Kabupaten Malang. Desa ini memiliki luas wilayah 344.983 ha, berada pada ketinggian $600 \mathrm{~m}$ Dpl dan memiliki curah hujan sebesar $2500 \mathrm{~mm} / \mathrm{th}$. Jumlah penduduk desa ini sebanyak 6.779 jiwa dan terbagi dalam 1.898 kepala keluarga. Dari segi sosial ekonomi, mata pencaharian penduduk desa Sukoanyar, mayoritas adalah petani dan buruh tani (50\%), karyawan swasta (23,5\%), pedagang (10\%) dan lain-lain. Luas lahan pertanian di Desa Sukoanyar adalah sebesar 246.610 ha, dengan jenis tanaman padi dan palawija. Potensi sumber daya alam terbesar yang dimiliki oleh Desa Sukoanyar dari sektor pertanian adalah jenis tanaman padi yaitu seluas 82.203 ha yang kebutuhan airnya diambil dari embung dengan jaringan irigasi teknis.

Rehabilitasi Jaringan Irigasi Desa adalah kegiatan perbaikan/penyempurnaan jaringan irigasi desa guna mengembalikan/meningkatkan fungsi dan pelayanan irigasi seperti semula atau menambah luas areal pelayanan. Rehabilitasi jaringan irigasi secara partisipatif merupakan wujud pemberdayaan masyarakat tani secara terencana dan sistematis untuk meningkatkan kinerja pengelolaan jaringan irigasi. Proses pemberdayaan dimulai dari perencanaan, pelaksanaan konstruksi, dan pengelolaan jaringan irigasi dengan melibatkan peran masyarakat sebagai pelaksana kegiatan. 


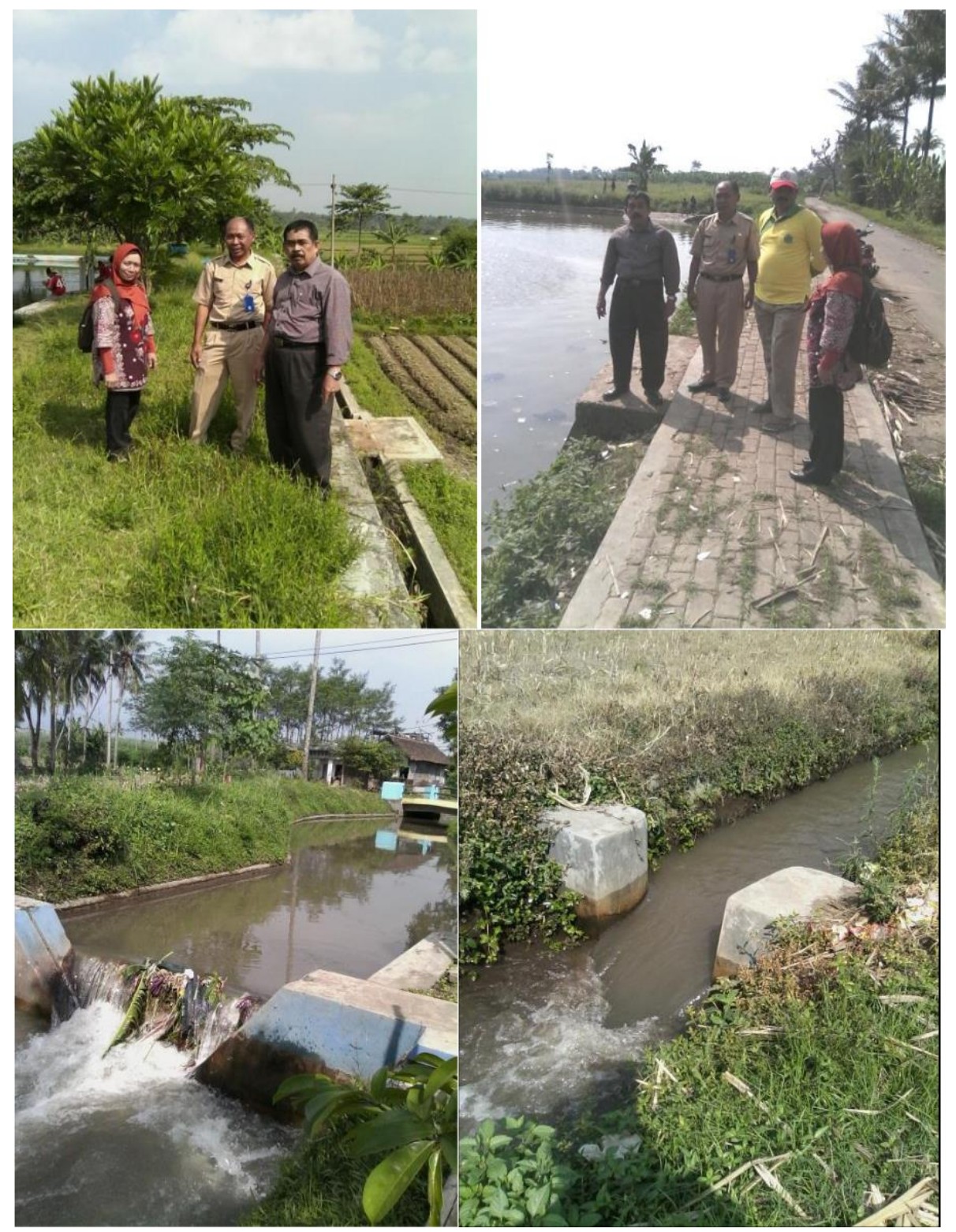

Gambar 1. Kondisi Jaringan Desa Sukoanyar, Pakis Kab. Malang

Hasil survey kondisi aktual di lapangan (Gambar 1,2) menunjukkan bahwa untuk Desa Sukoanyar berpotensi menjadi Desa Sejahtera Mandiri sesuai dengan program yang dicanangkan oleh Kemensos yang bekerjasama dengan Universitas Islam Malang karena memiliki beberapa faktor pendukung antara lain: (1) Potensi pasar yang luas, karena padi merupakan kebutuhan pokok masyarakat Indonesia, (2) Kondisi lahan yang subur sebagai modal dasar produktifitas pertanian, (3) Akses pemasaran yang mudah (4 km ke ibukota kecamatan, $37 \mathrm{~km}$ ke ibukota kabupaten dan $16 \mathrm{~km}$ ke pusat kota Malang), (4) Bibit padi diperoleh dari dinas pertanian dan (5) Ketersediaan embung sebagai sumber irigasi di desa tersebut. Namun demikian air dari embung yang didistribusikan melalui jaringan 
irigasi keadaan jaringan pada Desa Sukoanyar banyak yang perlu diperbaiki karena dimensi saluran dan dinding saluran sudah berubah dan rusak sehingga menyebabkan kebocoran air sehingga air tidak dapat sampai pada sawah ssesuai dengan kebutuhan tanaman. Disisi lain juga terdapat masalah yang ditemui dalam pelaksanaan budidaya pertanian di Desa Sukoanyar yang berkaitan dengan pelaksanaan teknis. Permasalahan ini dapat diidentifikasi dari masing-masing kelompok tani yang terbentuk terutama adalah pemberian air pada lahan sawah petani. Pada desa Sukoannyar telah terbentuk kelompok Tani yaitu Kelompok Tani Dewi Ratih I. Kelompok tani Dewi Ratih I mengalami beberapa masalah antara lain adalah debit irigasi yang sering tidak sesuai dengan kebutuhan. Jenis tanaman sangat menentukan jumlah air irigasi yang dibutuhkan, sebagai contoh untuk tanaman padi maka kebutuhan air irigasi akan lebih besar jika dibanding dengan palawija. Masalah tersebut sering kali terjadi karena tidak adanya koordinasi antar sesama petani serta tidak adanya koordinasi dengan pihak pengairan. Jika supply air tidak sesuai dengan kebutuhan tanaman, maka akan berakibat turunnya kualitas hasil panen bahkan terjadi kegagalan panen. Oleh karena itu dibutuhkan rehabilitasi jaringan irigasi terutama pada saluran tersier.

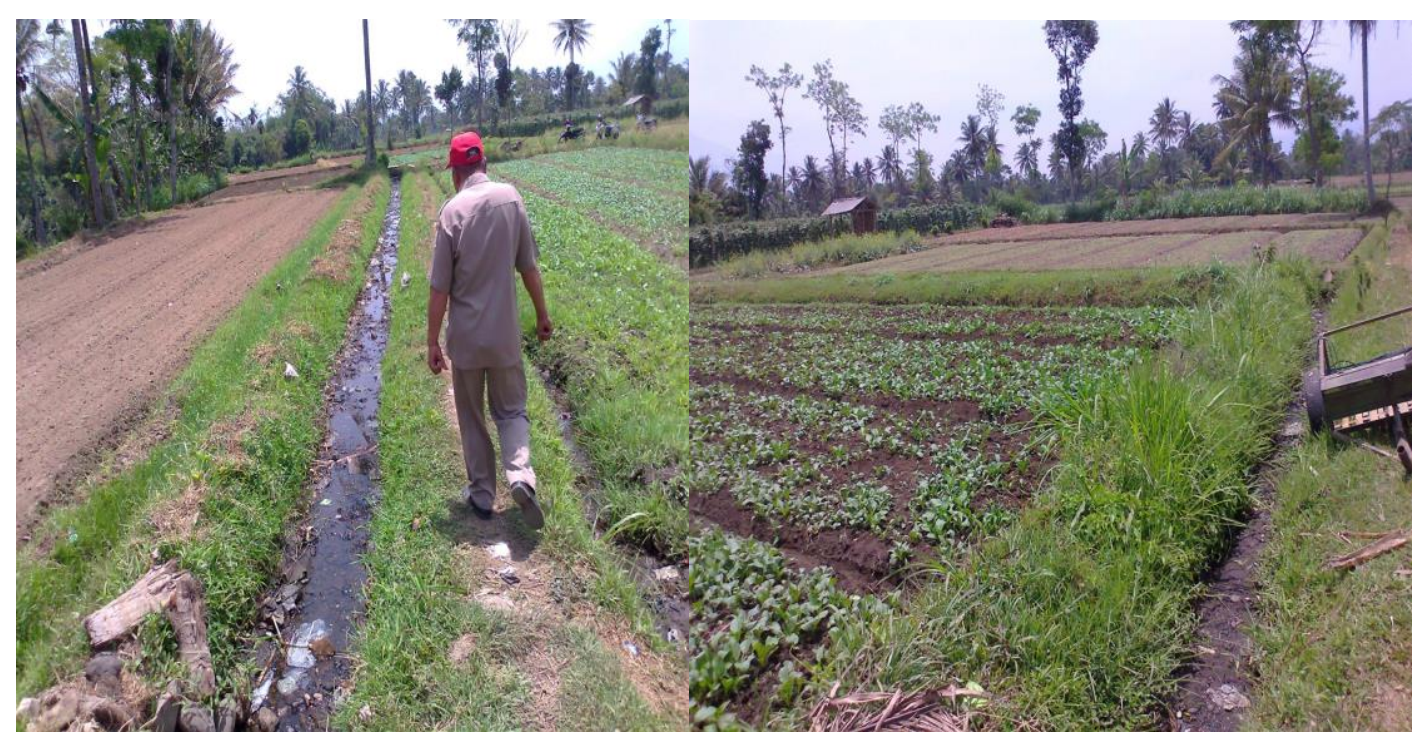

Gambar 2. Kondisi saluran tersier dan kwartier

Sistem Irigasi adalah syarat vital dalam sektor pertanian, masalah utama dalam sistem irigasi adalah0 ketersediaan air yang tidak tak terbatas, sehingga penggunaan air secara efisien merupakan hal yang penting tanpa mengurangi produktifitas hasil panen. Keterbatasan air untuk irigasi inilah yang menjadikan UPT SDA dan Irigasi berkewajiban mengatur debit air untuk irigasi setiap tahunnya, ketersediaan air yang melimpah pada 
musim penghujan dan minimnya air pada musim kemarau harus bisa diperhitungkan agar kegiatan pertanian tetap bisa berjalan secara produktif sepanjang tahun (Asdak. ,2007). Untuk menjaga produktifitas pertanian diperlukan koordinasi dan komunikasi antara petani dengan pihak irigasi, hal ini untuk mensingkronkan pola tanam petani dengan kondisi air irigasi yang tersedia sehingga tidak terjadi gagal panen akibat kurangnya supply air. Pada pelaksanaannya komunikasi dan koordinasi petani dengan pihak irigasi berjalan kurang lancar.

\subsection{Urgensi Permasalahan Prioritas}

Berdasarkan hasil diskusi dengan kelompok tani mitra, maka permasalahan prioritas yang akan ditangani adalah sebagai berikut:

1. Kurangnya beberapa sarana vital pada jaringan irigasi tersier

Dari ketiga kelompok tani, permasalahan umum yang dihadapi adalah kurangnya sarana vital pada jaringan irigasi tersier yaitu saluran tersier tidak sesuai dengan standart secara teknis dan perlu segera dilakukan perbaikan atau rehabilitasi saluran.

2. Terbatasnya pengetahuan dan teknologi pada kelompok tani

Beberapa teknologi dalam budidaya pertanian sudah diketahui oleh beberapa anggota kelompok tani, tetapi masih belum memahami cara pemberian air sesuai dengan pola tanamnya. Pola tanam yang terjadi pada saat ini kurang efektif sehingga hasil panen yang didapat kurang maksimal. Contoh permasalahan lain, tidak stabilnya debit air irigasi yang dialami oleh kelompok tani Dewi Ratih I, ternyata dikarenakan sedimentasi pada saluran irigasi dan pembagian air di bagunan bagi tersier, sehingga diperlukan penyuluhan pada pola tanam. (Gani, S. 2007)

\section{SOLUSI DAN TARGET LUARAN}

Berdasarkan urgensi masalah prioritas, maka solusi yang ditawarkan dibagi berdasar subsistem sebagai berikut:

1. Sub sistem pengadaan sarana jaringan irigasi vital

Pada kondisi aktualnya, beberapa sarana masing-masing kelompok telah tersedia baik secara mandiri maupun bantuan program dari Dinas Pertanian dan Perkebunan maupun Dinas PU Sumber Daya Air Kabupaten Malang. Pengelolaan jaringan irigasi tersier merupakan tanggung jawab petani pemakai air. Dalam hal perkumpulan petani pemakai air belum mampu membiayai seluruh atau sebagian kegiatan pengelolaan irigasi. Dengan adanya 
pengadaan sarana jaringan irigasi vital berupa bantuan rehabilitasi saluran tersier, diharapkan akan meningkatkan efisiensi penggunaan air irigasi sehingga produktifitas dan pola tanam akan lebih terkontrol (Fathan, N., dan Riman.1997).

\section{METODE PELAKSANAAN}

Dalam pelaksanaan program pengabdian di desa Sukoanyar adalah melakukan pendampingan dan subsidi bahan untuk rehabilitasi salah satu saluran tersier dengan melakukan pendekatan dan prinsip partisipatif, transparansi bersama kelompok Tani Dewi Ratih I. Program yang dilaksanakan harus dapat dipertanggungjawabkan dalam hal ketepatan sasaran, waktu, pembiayaan, dan mutu pekerjaan sehingga kegiatan pendampingan rehabilitasi saluran perlu melibatkan unsur pelaksana tertentu agar indikator kinerja dapat tercapai dengan harapan dengan selesainya rehabititasi ini masyarakat dapat memanfaat secara optimal prasarana irigasi yang ada.

\section{Ruang Lingkup Pekerjaan}

1. Memberikan bantuan pendampingan rehabilitasi kepada Kelompok Tani Dewi Ratih yaitu:

- $\quad$ survey pada jaringan irigasi yang akan direhabilitasi dan DED,

- penyusunan Rencana Kerja,

- pelaksanaan pekerjaan fisik di lapangan,

- pengawasan pelaksanaan fisik di lapangan,

- Koordinasi dengan Himpunan Petani Pemakai Air, dan

- Monitoring;

2. Membantu Petani dalam penyelesaian permasalahan di lapangan dalam pelaksanaan rehabilitasi saluran tersier;

3. Evaluasi dan monitoring kegiatan.

Evaluasi dan monitoring kegiatan dilakukan dengan melibatkan anggota pelaksana dan penyuluh Dinas Pekerjaan Umum Sumber Daya Air Kabupaten Malang.

\section{HASIL DAN PEMBAHASAN}

Dalam rangka upaya peningkatan produksi pertanian, salah satu program yang dilaksanakan yaitu Rehabilitasi Jaringan Irigasi (RJI) yang merupakan faktor penting dalam proses usaha tani 
yang memiliki dampak langsung terhadap peningkatan luas areal tanam adapun tahapan kegiatan adalah:

\section{Pembentukan Tim Teknis/Korlap}

Tim teknis dibentuk oleh Kepala Dinas PU Sumber Daya Air Kabupaten Malang UPT Tumpang yang terdiri Kepala Dinas PU Sumber Daya Air UPT Tumpang, Ketua HIPA Tumpang dan Ketua Kelompok Tani Dewi Ratih I.

\section{Tahap Pelaksanaan}

Tahapan pelaksanaan kegiatan Rehabilitasi Jaringan Irigasi sebagai berikut:

\section{a. Survei, Investigasi dan Desain (SID) Sederhana}

1) Pelaksanaan SID dilaksanakan oleh tim teknis/koordinator lapangan dengan berkoordinasi instansi terkait.

2) Pelaksanaan SID disesuaikan dengan dana yang ada karena sifatnya adalah bantuan baik dari instansi yang terkait akan tetapi diharapkan partisipasi masyarakat adalah yang paling dominan.

3) Laporan hasil SID memuat:

- Letak lokasi berdasarkan daerah administratif dan koordinat garis lintang dan bujur dengan menggunakan Global Positioning System (GPS).

- Luas layanan oncoran (command area) yang akan diairi.

- Gambar/sketsa/peta lokasi sederhana.

- Desain sederhana konstruksi Rehabilitasi Jaringan Irigasi yang akan dibangun.

- Rencana Anggaran Biaya (RAB).

- Rencana Usulan Kegiatan (RUK).

\section{b. Penyusunan Rencana Usulan Kegiatan (RUK)}

Penyusunan RUK dilaksanakan dengan musyawarah

P3A/GP3A/Poktan/Gapoktan dengan bimbingan tim teknis/koordinator lapangan. RUK disusun berdasarkan kebutuhan bahan dari hasil SID antara lain memuat rencana: (i) komponen jaringan irigasi (tersier) yang akan direhabilitasi (ii) dimensi saluran, (iii) kebutuhan bahan material, (iv) tenaga kerja (v) sewa alat (jika dibutuhkan), (vi) jumlah biaya, (vii) sumber biaya (bantuan pemerintah dan partisipasi masyarakat) dan (vii) waktu pelaksanaan.(Anonim, 2019)

RUK yang telah disusun harus disetujui oleh tim teknis/koordinator lapangan dan diketahui oleh Kepala Dinas Kabupaten. 
Hal - hal yang harus diperhatikan dalam penyusunan RUK, meliputi:

1) Biaya pembuatan lining saluran diarahkan kepada pemanfaatan anggaran yang tersedia seefisien mungkin, namun tetap memperhatikan keamanan dari aspek teknis kontruksi/bangunan, dengan menyesuaikan ketersediaan bahan/ material di wilayah masing-masing.

2) Pembersihan lokasi, pembelian alat bantu kerja, perapihan kembali serta dokumentasi dan pelaporan dibiayai secara swadaya oleh P3A/GP3A/Poktan/Gapoktan.

\section{Pelaksanaan Konstruksi}

Proses pelaksanaan konstruksi kegiatan Rehabilitasi Jaringan Irigasi meliputi :

a. Pekerjaan persiapan, meliputi pengukuran lahan dan pembersihan lokasi;

b. Pembelian bahan material;

Pembelian bahan material harus sesuai dengan spesifikasi atau rincian material dan barang yang telah disepakati dan disetujui dalam RUKK.

c. Mobilisasi Alat dan Tenaga Kerja;

Mobilisasi alat harus mengakomodasi jarak dan trasnportasi sampai dengan lokasi kegiatan. Untuk tenaga kerja diharapkan dari partisipasi anggota P3A/GP3A/Poktan/ Gapoktan. Partisipasi dari anggota dapat diberikan insentif tenaga kerja yang nilainya ditentukan berdasarkan musyawarah antara P3A//GP3A/Poktan/ Gapoktan. Jadwal kebutuhan tenaga kerja harus disesuaikan dengan target jumlah dan waktu.

d. Konstruksi Rehabilitasi Jaringan Irigasi;

Pelaksanaan konstruksi Rehabilitasi Jaringan Irigasi dilaksanakan secara swakelola oleh P3A/Poktan secara bergotong - royong dengan memanfaatkan partisipasi dari anggotanya. Pelaksanaan disesuaikan dengan pekerjaan yang dibutuhkan adalah merehabilitasi jaringan irigasi, yang meliputi saluran irigasi pembawa (conveyance) hanya 1 saluran tersier.

Bahan material yang dapat digunakan untuk pembuatan pasangan saluran, antara lain :

a) Pasangan batu

Tebal minimal pada pasangan batu adalah $30 \mathrm{~cm}$.

b) Beton Tebal minimal pada pasangan beton adalah $7 \mathrm{~cm}$. 


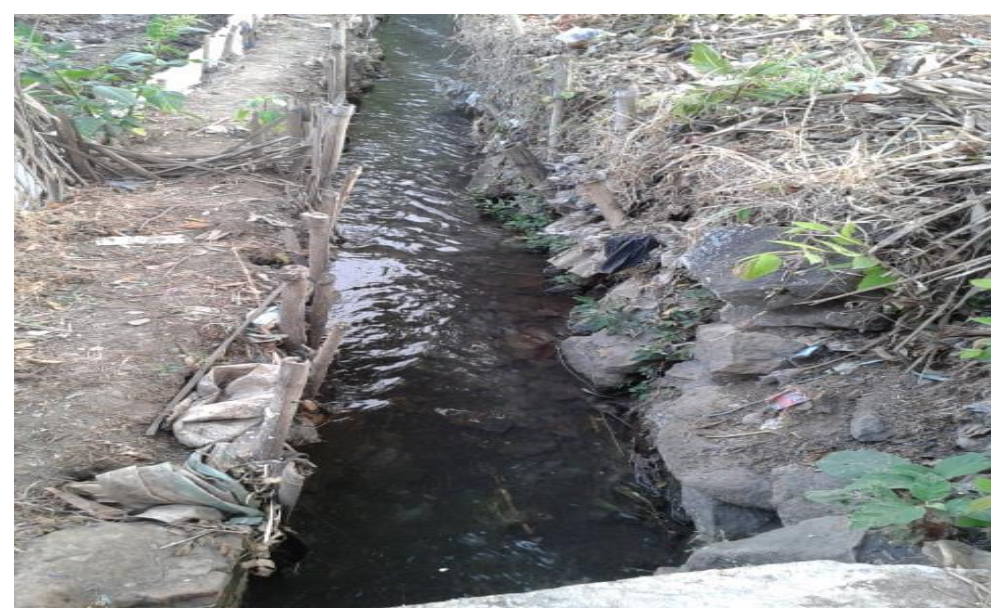

Gambar 3 Keadaan saluran tersier sebelum rehabilitasi

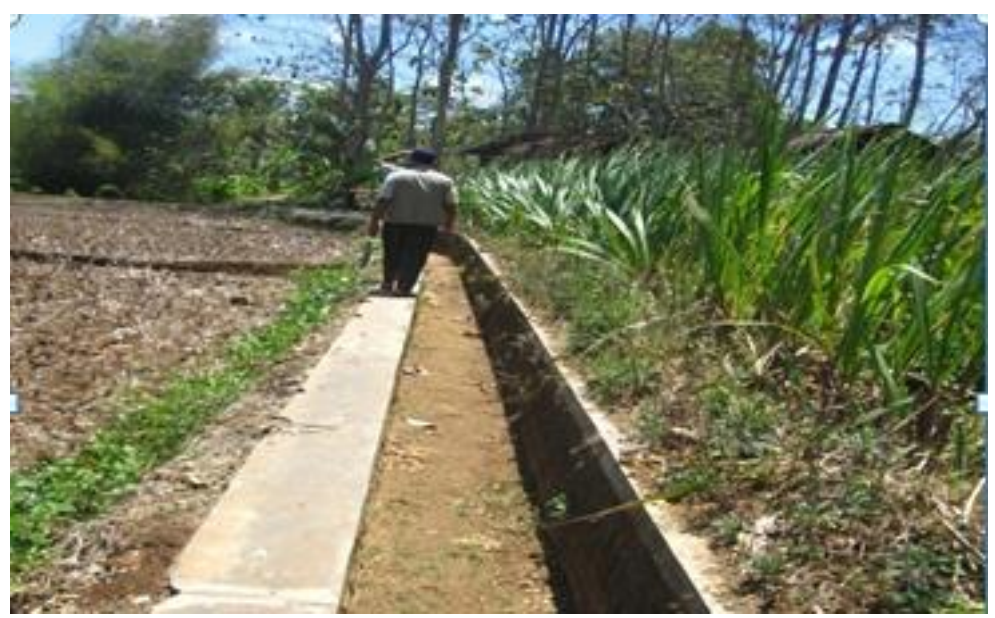

Gambar 4. Keadaan saluran setelah rehabilitasi

\section{KESIMPULAN}

Kegiatan pengabdian pada Masyarakat dengan mitra pelaksanaann kegiatan rehabilitasi saluran di desa Sukoanyar Kecamatan Tumpang Kabupaten Malang telah berhasil dilaksanakan dengan baik. Dampak perubahan dari kegiatan ini adalah tersedianya saluran tersier yang telah direhabilitasi dan pengelolaan sesuai dengan aturan yang ada yaitu HIPPA Dewi Ratih I dengan harapan distribusi air lebih baik da nada efisiensi air irigasi.

\section{DAFTAR PUSTAKA}

Anonim. (1977). Pedoman Bercocok Tanam Padi, Palawija, Sayur-sayuran. Badan Pengendali Bimas Departemen Pertanian.Jakarta

Anonim. (1986). Kriteria Perencanaan Jaringan Irigasi KP-01,Kriteria Perencanaan Penunjang. Ditjen. Pengairan Dep. PU Galang Persada. Bandung. 
Anonim. (2009). Laporan Kegiatan Alokasi Air DAS Amprong. Unit Pengelolaan SDA Wilayah Sungai Bango Gedangan. Dinas PU Pengairan Provinsi Jawa Timur. Malang.

Anonim. (2019). Pedoman Teknis Rehabilitasi Jaringan Irigasi. Direktorat Jenderal Prasarana dan Sarana Pertanian Kementerian Pertanian.

Asdak. (2007). Hidrologi dan Pengeloalaan Daerah Aliran Sungai. Yogyakarta: Gajah Mada University Press.

Fathan, N., dan Riman. (1997). Analisis Operasi Pelayanan Pembagian Air Irigasi. Media Teknik No. 4 Tahun XIX.

Gani, S. (2007). Perencanaan Sistem Irigasi Rotasi untuk Penyaluran Air secara Proporsional. Alami Vol. 12 No 1. 